\title{
Health Summits in Global Health Governance
}

\author{
Zhang Yanan, Ma Mengdi, Xie Qian, Chen Xuyu and Tan Xiaodong* \\ School of Health Sciences, Wuhan University, China \\ Received: 無: November 06, 2018; Published: 盽: December 13, 2018 \\ *Corresponding author: Tan Xiaodong, School of Health Sciences, Wuhan University, China
}

\section{Abstract}

Global health governance is accompanied by the formation of global health networks and global health regimes that shaping the way the problem and solutions understood and convincing governments, international organizations and other global actors to address these issues. Health summit refers to international conference attended by the top leaders of all countries, which involving multinational or multilateral health issues involving the highest leaders of all countries and expected to reach certain consensus or certain common programmatic documents. Health summits functions as [1] provides a coordination platform for sharing understanding of health issues between multiple governance bodies and governance mechanisms, [2] its participants play a leading role that ensures the political coalition and formation of issues' policy. As health summits is critical for global health governance, we advocate that more attention should be paid on health summits when dealing with global health issues.

\section{Introduction}

Global health, referring to those health issues which transcend national boundaries and governments and call for actions on the global forces that determine the health of people, is seen as a shared global challenge [1]. Global health governance rises as the way to address acute infectious diseases' outbreak and spread, chronic noninfectious diseases' prevention and improvement of human's quality of life as well as prolongation of life [2]. Global health governance is accompanied by the formation of global health networks and global health regimes that shaping the way the problem and solutions are understood and convincing governments, international organizations and other global actors to address these issues [3,4]. It is worth mentioning that the agreement on the Paris agreement on climate change, the Sustainable Development Goals (SDGs), the Framework Convention on Tobacco Control have played a positive role in global health governance. A common point in reviewing the major achievements is that they are all based on the platform of the summit. Therefore, what is the role of health summits? And, how about the health-related summits in addition to these famous international or regional health summits?

\section{Health Summit: A Platform and A Catalyst}

Health summit refers to international conference attended by the top leaders of all countries, which involving multinational or multilateral health issues involving the highest leaders of all countries and expected to reach certain consensus or certain common programmatic documents [5]. As the decision-making body and supreme forum of international organizations, the summit not only plays an important role in global governance, but also participates in global governance through its own international organizations [5,6]. Especially for some global forum-based international organizations, the summit is not only the core of the organization, but also an important symbol of the organization. These summits are themselves important participants and promoters of global governance. Summit has become an important and irreplaceable platform for the international community to deal with global health issues. Briefly, the summit has two advantages for global health governance:

Firstly, the summit provides a coordination platform for sharing understanding of health issues between multiple governance bodies and governance mechanisms. How will our global health governance function in the face of multiple governance bodies or millions of people on the move as they challenge borders, financing mechanisms, social systems and political positions? The platform is to achieve the highest level of coordination and consensus in global health governance on an independent and equal basis. Secondly, Summit participants play a leading role - mainly function through the summit's constitution, consensus and commitment - as they are usually leaders of countries or international organizations $[4,7]$. The summit can make quick decisions on emergency health problems globally, control and resolve the crisis. As for the major issues of human health, the summit helps all participants to identify priority areas and basic directions, to decide on the internal structure and operation, and to cooperate with other countries or international organizations to benefit human health. At the beginning of the 
new millennium, global leaders gathered in the United Nations to discuss the broad vision of multifaceted fight against poverty.

This vision then was developed into eight Millennium Development Goals (MDGs), which have been leading the world development framework for the past 15 years. Hereafter, the post 2015 agenda of Sustainable Development Goals (SDGs) was devoted to combating poverty, protecting the planet and ensuring the peace and prosperity of human through concerted action which were proposed at the end of the MDGs. These 17 goals of SDGs were built on the achievements of the MDGs add new areas such as climate change, economic inequality, innovation, sustainable consumption, peace and justice. These goals will guide the policy development and financial use of the United Nations Development Program over the next 15 years.

\section{Health Summit: A Neglected Global Governance Oppor- tunities}

Tracing the summits held around the world, we found that those summits have discussed and responded to global issues in addition to seeking cooperation, which are related to fields like political, economic, cultural, healthy, national security, science and technology, and all others. According to our statistics, since 2016, more than 40 global summits worldwide has been held, the theme of the summits and issues related to economic, political and security environment and so on, but there are very few about health governance.

\section{Seize the Opportunity}

As global health remains one of the most pressing problems of our time, we have to seize the advantage of summit in that it is a stage where the global elites gather together, the action guidance was made, and the cooperation consensus was reached. We suggest that more attention should be paid on health summit or healthrelated summit when it comes to global health governance at this global community that no country, acting alone, can adequately protect the health of its citizens or significantly ameliorate the deep problems of poor health in various countries. We expect that health summit platform can make a difference in global health governance.

\section{Conclusion}

Health summits plays a key role in global health governance as its participants play a leading role that ensures the political coalition and formation of issues' policy, which provides a coordination platform for sharing understanding of health issues between multiple governance bodies and governance mechanisms. In the context of globalization and global health governance, we call on every actor to seize the opportunity to work together to address the health issues of humanity.

\section{Acknowledgement}

We express our appreciation to the major online platforms for helping us count the health-related conferences

\section{References}

1. Centre EF (2014) European Perspectives on Global Health: A Policy Glossary p. 1-72.

2. Kickbusch I (2016) Global Health Governance Challenges 2016 - Are We Ready? Int J Health Policy Manag 5(6): 349-353.

3. Shiffman J, Schmitz HP, Berlan D, Smith SL, Quissell K, et al. (2016) The emergence and effectiveness of global health networks: findings and future research. Health Policy Plan 31: 110-123.

4. Tosun J (2018) Polycentrism in Global Health Governance Scholarship; Comment on "Four Challenges That Global Health Networks Face". Int J Health Policy Manag 7(1): 78-80.

5. Chattu V (2017) The rise of global health diplomacy: An interdisciplinary concept linking health and international relations. Indian Journal of Public Health 61(2): 134-136.

6. Jones CM, Clavier C, Potvin L (2017) Adapting public policy theory for public health research: A framework to understand the development of national policies on global health. Soc Sci Med 177: 69-77.

7. Jones CM, Clavier C, Potvin L (2017) Are national policies on global health in fact national policies on global health governance? A comparison of policy designs from Norway and Switzerland. Bmj Global Health 2(2): e000120.
ISSN: 2574-1241

DOI: 10.26717/BJSTR.2018.12.002202

Tan Xiaodong. Biomed J Sci \& Tech Res

This work is licensed under Creative

Commons Attribution 4.0 License

Submission Link: https://biomedres.us/submit-manuscript.php

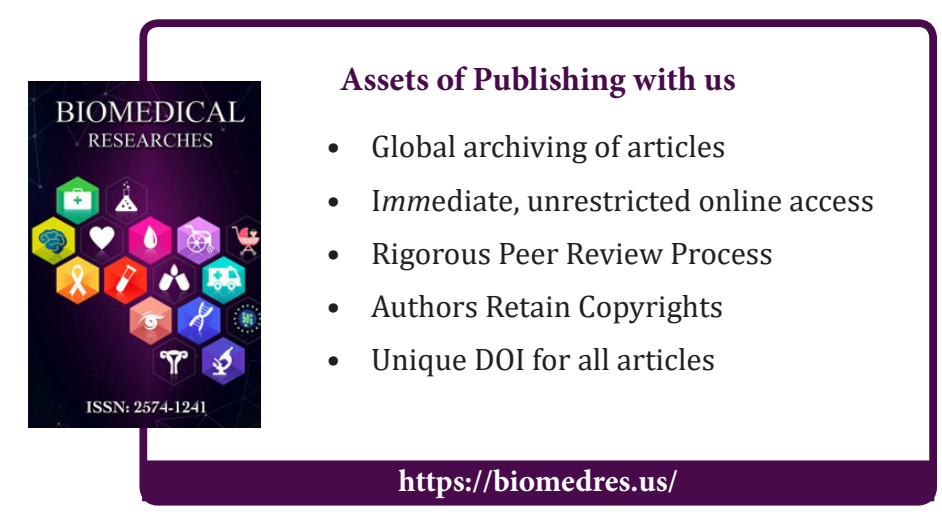

